\title{
La seguridad alimentaria y su aplicación en países de la C uenca del Pacífico
}

\begin{abstract}
El concepto de seguridad alimentaria es utilizado como instrumento analítico para interpretar el discurso y analiza las formas de aplicación de las políticas alimentarias en los niveles global, nacional, regional y familiar. El autor toma como puntos de referencia las propuestas de organismos internacionales como el Banco Mundial y la FAO , así como casos de Japón, China, Estados U nidos y México. El trabajo muestra que no obstante el avance logrado en la clarificación del problema de inseguridad alimentaria, ello no ha llevado a propuestas realistas de solución. Las estrategias convencionales, por lo general, reflejan los intereses de quienes las sustentan y/o el apego a esquemas tecnocráticos que no toman en cuenta los aspectos políticos y sociales. Concluye que la inseguridad alimentaria es producto de un sistema de distribución muy inequitativo, de acciones erróneas de política y de fenómenos destructivos como las conflagraciones bélicas y que, en última instancia, la seguridad alimentaria es un asunto de economía política que sólo puede ser resuelto por la acción del Estado: hacia arriba con la coordinación con otros Estados y hacia abajo con el apoyo de la sociedad organizada.
\end{abstract}

\section{Roberto H ernández H ernández}

\section{ntroducción}

Uno de los más lacerantes contrastes del mundo actual se conoce como la paradoja del hambre. Ésta se manifiesta en el hecho de que, mientras por una parte, en los países desarrollados y algunos subdesa-

Ponencia presentada en el coloquio internacional A gricultura y Educación Superior en la Cuenca del

Pacífico, celebrado del 3 al 5 de octubre de 1994

en la Universidad Autónoma de Chapingo rrollados se acumulan grandes cantidades de alimentos -y una proporción importante de los mismos tiene que ser convertida en forraje o destruida- por la otra, varios millones de gente (especialmente niños) mueren cada año de hambre o de enfermedades relacionadas con ésta. La inequitativa e ineficiente distribución de alimentos es el factor más evidente de esta 
circunstancia, como lo demuestra el hecho de que si la producción mundial de cereales se distribuyera equitativamente entre la población del planeta, cada individuo podría disponer de un kilogramo por día (FAO 1993), equivalentea dos veces los requerimientos mínimos (Alamgir y Arora 1991:2).

Los temas sobre la producción, distribución y consumo de alimentos, así como la políticas que los determinan, se abordan en este trabajo desde la óptica de la seguridad alimentaria. Ésta se define y delimita en la primera parte; en la segunda, se analiza la percepción de algunos países de la Cuenca del Pacífico sobre la seguridad alimentaria, así como las circunstancias materiales (dotación de recursos, infraestructura, etcétera), políticas, tecnol ogias que la sustentan, en grado y forma. Para la delimitación del concepto se va de lo general a lo particular, esto es, del análisis de la seguridad alimentaria global, nacional, regional y familiar. Posteriormente se examinan las circunstancias de J apón y China, del lado occidental de la Cuenca del Pacífico y Estados Unidos y México, de la parte oriental dela Cuenca.

Este enfoque tiene dos objetivos: contribuir a darle firmeza conceptual a las nociones de seguridad y autosuficiencia alimentaria y analizar las formas como se concibe y se aplica en países de la Cuenca del Pacífico con diferencias sustanciales en aspectos como recursos, sistema político y grado de desarrollo.

\section{Seguridad alimentaria: los planteamientos del problema}

El concepto seguridad alimentaria surge y se populariza a principios de los setenta, cuando se da la llamada crisis mundial de alimentos ${ }^{1}$. Éste contiene en sí mismo otras nociones, como autosuficiencia, soberanía o independencia alimentarias. Sin embargo, tales conceptos, que tienen una connotación particular, se utilizan -consciente o inconscientemente, por descuido o ignorancia- como sinónimos unos de otros, provocando con ello más confusiones que las del propio problema que se intenta

1 La "crisis mundial de alimentos" de 1972-1973, que se originó por la disminución en las cosechas de cereales, tuvo consecuencias desastrosas para varios países subdesarrollados, no tanto por la carencia real de alimentos, sino más bien por el aumento desmesurado de los precios de los granos que se dio por el pánico en que cayeron los mercados internacionales de estos bienes. 
analizar con estos instrumentos. De ahí la necesidad de comenzar por una definición y delimitación de los mismos.

\section{El enfoque global de la seguridad alimentaria}

Desde un enfoque gl obal, la seguridad al imentaria se relaciona con la capacidad de la Tierra para producir alimentos que requiere el total de la población mundial. Dada la disparidad de recursos naturales, nivel de desarrollo tecnol ógico, densidad demográfica, clima y grado de efectividad de las políticas diseñadas y aplicadas por los gobiernos, la producción mundial es desigual. En consecuencia, en la seguridad alimentaria intervienen factores como exportación e importación de productos, oferta y demanda regionales, niveles de precios internacionales, disponibilidad de divisas y capacidad de financiamiento, tipo de logística e infraestructura para movilizar las mercancías, además de los niveles de producción.

Hasta ahora, la Tierra ha mostrado tener la capacidad suficiente para alimentar la población que la habita. Desde principios de los años sesenta, por ejemplo, la producción mundial de alimentos ha mantenido, y en ocasiones excedido, el rtimo de crecimiento de la población (FAO 1993). Aunque, evidentemente, algunas regiones y países presentan crecimientos desiguales y aun decrementos (Europa Oriental y África). La situación general de la región de la Cuenca del Pacífico puede apreciarse en el siguiente cuadro. 


\section{Índices de incremento en la producción de alimentos y de la población en la C uenca del Pacífico, 1992 $(1979-81=100)$} Región o país Producción Población

$\begin{array}{lll}\text { Mundo } & 127.2 & 123.2 \\ \text { A sia } & 151.8 & 127.4 \\ \text { O ceanía } & 116.2 & 122.2 \\ \text { A mérica del Sur } & 135.6 & 132.4 \\ \text { N orte y Centro A mérica } & 115.2 & 119.4 \\ \quad \text { Centro A mérica } & 114.6 & 131.2 \\ \quad \text { México } & 127.1 & 134.8 \\ \quad \text { Estados Unidos } & 113.2 & 113.2 \\ \quad \text { Canadá } & 117.2 & 115.2\end{array}$

Fuente: FAO . Serie Informática EstadísticaRoma, 1993.

Como se desprende del cuadro anterior, para 1992, la producción mundial de alimentos fue superior al aumento de la población en cuatro puntos porcentuales; en Asia 24.4, en Oceanía -6.0, en América del Sur 3.1, en Centro América -16.6, en México -7.7 y en Canadá 2.0 puntos porcentuales; por lo que respecta a Estados Unidos, el índice de crecimiento poblacional fue igual al de la producción de alimentos.

La inseguridad alimentaria que actualmente se presenta en algunos países de Europa y África evidentemente responde a acciones erróneas o destructivas del hombre.

Una controversia fundamental sobre la seguridad alimentaria está en las propuestas teóricas de eliminar los controles para permitir la acción del mercado y la práctica concreta de la seguridad alimentaria que obliga a las élites gubernamentales a actuar con cautela ante posibles cambios en los sistemas de control. Teóricamente, si se liberalizara el comercio agrícola, la seguridad al imentaria se vería favorecida, dado que declinaría el coeficiente de variación de los precios, se incrementarían las oportunidades de comercioy, al el evarse los precios, 
favorecería la participación de los países subdesarrollados en la producción de bienes básicos, aumentando con ello el poder de compra de la gente pobre (Hazell 1993:41). Aunque los resultados de intrumentar una política de liberalización son discutibles, los supuestos lo son más: parten de la liberalización de los mercados de los países de la OCDE y subdesarrollados.

De acuerdo con la idea de la liberalización mercantil, los países en desarrollo que importan alimentos y toman los precios de los mercados mundiales pueden lograr la seguridad alimentaria a un costo inferior si modifican (sic) la cantidad de importaciones, al mismo tiempo que mantienen una existencia tapón relativamente pequeña, lo cual implica conservar activos líquidos en forma de reservas de divisas extranjeras y no en forma de alimentos (Siamwalla y Valdés 1991:238). Cuando se presente el problema de inseguridad alimentaria, el país importador de alimentos no necesita desviar sus propios recursos a inversiones líquidas, sino que puede pedir prestado a medida que se presente la necesidad.

Aunque quienes apoyan la idea de las adquisiciones en el mercado internacional reconocen que la capacidad total de pedir prestado se ve limitada a largo plazo por la riqueza del país o del hogar, el acceso a una línea de crédito determinada tenderá a lograrse a expensas del crédito para inversiones a más largo plazo (ibid, 238).

La disminución en las cosechas de 1972, que afectó la disponibilidad mundial de alimentos provocando pánico en los mercados mundiales de granos, y hambre en varios países, fue un claro indicio de que la seguridad alimentaria requiere de un mayor control por parte del Estado.

En la práctica, los países que han logrado reforzar su seguridad alimentaria Io han hecho incrementando su producción interna. En el decenio de los setenta, después de la "crisis" de alimentos, la percepción que sobre la seguridad alimentaria adquirieron varios países desarroIlados los Ilevó a estimular su producción interna, hecho que incidió radicalmente en el cambio de las estructuras del comercio mundial de alimentos.

El papel estratégico que la agricultura fue teniendo en el abastecimi ento de los requerimientos alimenticios de una población cada vez 
mayor, le confirió a la actividad un valor más de seguridad nacional que de rentabilidad económica. De ahí el esfuerzo de los países desarrollados por ampliar la producción mediante la aplicación de subsidios gubernamentales y una mejor administración de la actividad agrícola.

El caso más notable fue el de la Unión Europea, que en los setenta pasó de importante importador de cereales a exportador de grandes volúmenes (Schu 1986:129). En el decenio pasado sobresale el dinamismo de los países asiáticos en la producción de básicos.

En contrapartida, los casos más importantes de estancamiento y retroceso se dieron en algunos países de América Latina, África y Europa Oriental.

\section{La Seguridad Alimentaria Nacional}

La seguridad alimentaria nacional es la suma de las seguridades alimentarias regionales (subnacionales) y familiares. A nivel nacional, puede definirse como la certeza que tiene un país de disponer de los alimentos para hacer frente a los requerimientos cotidianos mínimos per cápita durante un periodo de referencia (un año, por ejemplo), y también para enfrentar cualquier disminución inesperada en un periodo limitado, generalmente de tres meses (Alamgir y Arora, 1991:7).

La seguridad al imentaria se define también como la habilidad que tiene un país o regi ón para asegurar, de manera oportuna y confiable, sobre una base de largo plazo, el acceso a la totalidad de la población de Ios alimentos nutricionalmente adecuados que requiere (Ruppel 1991:207). El Banco Mundial (1986) define a la seguridad alimentaria como el "acceso por toda la gente, en todo tiempo, al alimento suficiente para una vida activa y saludable".

Las definiciones de seguridad al imentaria por lo general incluyen dos elementos esenciales: por el lado de la oferta, la disponibilidad de alimentos y por el lado de la demanda, el acceso a éstos. A los dos elementos básicos Rukuni y Eicher (1988) Ios Ilaman Ia ecuación alimentaria, compuesta por: a) la disponibilidad de alimentos a través de la producción interna, almacenamiento y/o comercio, y b) el acceso a los alimentos a través de la producción interna, el mercado o la transferencia. 
A nivel nacional, la seguridad alimentaria involucra un adecuado abasto de alimentos a través de producción interna e importación de alimentos. Específicamente, las variables que determinan la disponibilidad son producción, importación, exportación y cambios en las existencias.

La producción de alimentos está determinada por la disponibilidad de la tierra, rendimiento de las cosechas (levantadas y potenciales), factores del medio ambiente nacional, así como por circunstancias soci opolíticas y administrativas. Las importaciones netas pueden ser comerciales, concesionadas (ayuda alimentaria) o transferencias de reservas estratégicas. De este modo, las importaciones están en función de la producción interna per cápita, los recursos en divisas, la situación de la oferta internacional y los precios de importación, la política gubernamental (por ejemplo, ubicación de las divisas para importación de alimentos e insumos productivos), planificación de las importaciones, la disponibilidad de ayuda alimentaria, la organización para hacer frente a las emergencias de seguridad alimentaria. Para un importador neto, un incremento inesperado en los precios internacionales de los granos al imentarios equivale a un detrimento de su seguridad alimentaria nacional. La experiencia ha mostrado que los incrementos en el precio de las importaciones y las reducciones en los mercados internacionales son causados por disminuciones en la producción de los principales países exportadores, reducción de las reservas internacionales, incremento en la demanda mundial, políticas internas de exportación e importación de los países, incremento en los costos de producción y la inflación internacional (Alamgir y Arora 1991:8).

La seguridad en materia de alimentos es diferente de la autosuficiencia. La seguridad puede estar o no relacionada con un alto grado de autosuficiencia alimentaria. La seguridad se refiere tanto a la capacidad productiva interna como a la ecónomica, para adquirir en el exterior los productos que complementen la oferta necesaria para cubrir las necesidades alimentarias de su población. Para la mayoría de los países, la producción interna de alimentos es menos estable que la disponibilidad de los mismos a nivel global. No obstante, muchos países han seguido la estrategia de ampliar su autosuficiencia como forma de reforzar su 
seguridad alimentaria, haciendo a un lado las teorías de la especialización y el intercambio basadas en las ventajas comparativas.

La búsqueda de la autosuficiencia, que algunos autores consideran económicamente "irracional", tiene sus propios objetivos y racionalidad. Las justificaciones de la autosuficiencia agrícola induyen: a) hacer frente al de riesgo y la inestabilidad de los mercados internacionales donde las fluctuaciones en las existencias y los altibajos en la demanda provocan grandes variaciones en los precios, b) protección a la agricultura nacional frente a mercados internacionales, que no reflejan los costos reales de producción ni las condiciones de las Ilamadas ventajas comparativas internacionales, sino más bien el capricho de quienes diseñan las políticas agrícolas en los países con altos niveles de ingreso, y c) prosecución de metas generales de desarrollo (Staatz 1991:18).

La autosuficiencia es unidimensional; el nivel de autosuficiencia puede incrementarse con la producción interna, con el incremento en la utilización de las existencias internas y con la reducción en el consumo de alimentos. La seguridad alimentaria tiene, en cambio, dos dimensiones: Ia suficiente disponibilidad de alimentos para una vida activa y saludable y la capacidad de toda la población de acceder a los alimentos. En consecuencia, la seguridad alimentaria considera, por una parte, la oferta total de productos alimenticios (producción, almacenamiento, importaciones), además de la oferta real; y por la otra, las necesidades de al imentos de toda la población, induyendo la demanda efectiva, o sea, la capacidad que proporciona el sistema para adquirir los alimentos (nivel es de ingreso, mecanismos de distribución, acceso a recursos y servicios y a programas específicos de distribución de alimentos).

El grado de autosuficiencia alimentaria es la proporción del consumo interno total de un producto o grupo de productos, en relación con la producción y el uso de las existencias internas en un periodo específico (Kellogg 1991:235); apreciación muy cercana a la metodología elaborada por la FAO para medir el grado de seguridad alimentaria de un país (FAO 1975).

La prosecución de la autosuficiencia tiene una relación directa con la capacidad estructural o de dotación de recursos de un país para producir los alimentos que requiere y con la memoria histórica de grandes 
déficits, provocados por calamidades naturales o circunstancias políticas extremas, entre las que se cuentan las guerras.

La noción de autosuficiencia también se ha utilizado para justificar o afianzar políticas agrícolas de carácter populista. En este sentido, el incremento de la producción se condiciona a una el evada participación y "democracia" de los trabajadores rurales, a una total distribución de la tierra por medio de expropiaciones y al trabajo comunitario. Asimismo, se ha utilizado como bandera política de varios países en vías de desarroIlo, deficitarios en alimentos que, imbuidos por los temores de la teoría de la dependencia y lastimados por los efectos de la "crisis mundial de alimentos", veían como única salida a la utilización del "food power" por parte de países superavitarios desarrollados, la producción interna -a cualquier costo- de los requerimientos de nutrición básica de la población.

La autosuficiencia, como parte o justificación fundamental de la política agrícola, se ha utilizado de manera general e imprecisa. Al momento de establecerse una política en este sentido, por lo común no se aclara si se trata de autosuficiencia de un solo grano al imentario básico, de un paquete de productos básicos, de todos los alimentos o de toda la cadena para producir los alimentos (por ejemplo, granos cerealeros para el ganado o fertilizante para la producción de granos), o incluso en todos los insumos para las industrias de insumos.

La soberanía e independencia alimentarias.- A nivel nacional frecuentemente se relaciona la seguridad al imentaria con la soberanía o independencia alimentarias. En este sentido, seguridad alimentaría sería el conjunto de condiciones -económicas, políticas y tecnológi cas- que garantizan la soberanía y la independencia alimentarias. O sea, la posibilidad real de un país de tomar, por sí y para sí, las decisiones bási cas en lo interno y lo externo, sobre esta materia (Aguayo y Michel 1990:11).

\section{La seguridad alimentaria regional}

A nivel regional (subnacional), que puede comprender varios estados y municipios, el concepto de seguridad alimentaria es un poco menos 
preciso que a los niveles nacional o familiar. Esto porque la relación con la ingesta individual de alimentos no siempre es obvia. La seguridad alimentaria regional significa disponer de suficientes alimentos para que las familias que integran un área determinada puedan hacer frente a sus requerimientos mínimos de consumo durante un periodo determinado. A este nivel, el concepto "mínimo" debe reflejar, cuando menos parcialmente, la estructura de gustos y preferencias de las familias.

La producción regional de alimentos es esencial para la seguridad alimentaria regional, a menos que el equilibrio alimentario del área en cuestión esté determinado por consideraciones de ventajas comparativas agroeconómicas. Sin embargo, la producción primeramente es del dominio de la unidad familiar, salvo en los casos en que ésta forme parte de un sistema de producción colectivo como son las granjas estatales o las cooperativas de producción en sus diversas modalidades (Alamgir y Arora 1991:7). Asimismo, puede presentarse una actividad limitada de producción alimentaria cuando se da una administración a nivel de puebl o o comunidad que asigna diferentes tareas a las familias o grupos de familias y que dispone de una estrategia de seguridad al imentaria suprafamiliar. Otras variantes que influyen en la seguridad alimentaria regional son: el mantenimiento de reservas alimentarias a nivel de pueblo, distrito o estado, por las entidades públicas o los comerciantes privados, los flujos de comercio privado entre las áreas y la obtención de productos en la región por parte de las entidades públicas y empresas paraestatales (Alamgir y Arora 1991:7).

Hay que tener en cuenta también que en muchos países los altos costos financieros y de transporte que origina el aislamiento geográfico de algunas zonas constituyen una forma de barrera comercial. En consecuencia, la estabilización de precios en las regionas más aisladas, donde los niveles de consumo son superiores a la producción, requieren de apoyos especiales de los gobiernos.

\section{La seguridad Alimentaria Familiar}

Una familia goza de seguridad alimentaria cuando tiene acceso físico y económico a alimentos suficientes para todos sus miembros y cuando no 
corre un riesgo excesivo de perder ese acceso (Naciones Unidas 1993:162). Aunque a nivel nacional la seguridad alimentaria depende de la disponibilidad de alimentos, independientemente de si provienen de la producción interna o externa a través de la importación. Una adecuada disponibilidad de alimentos a nivel nacional no necesariamente se convierte en una distribución equitativa entre las diferentes regiones y familias que integran un país.

La seguridad alimentaria familiar significa la disponibilidad de alimentos adecuados (aceptables culturalmente, seguros y nutricionalmente adecuados), así como la habilidad de la familia de tener un acceso estable a tales alimentos a través de su propia producción o adquisición. Así, disponibilidad y acceso estables son determinantes para la seguridad familiar. Las familias tendrán acceso estable a los alimentos si disponen de medios viables para procurarlos (ya sea producidos o adquiridos), sin que ello conduzca a la degradación del medio ambiente. Un acceso estable también es influenciado por mecanismos sociales informales de carácter local (por ejemplo, la estructura de distribución de alimentos) que prevenga a las familias de impactos periódicos, así como por la estabilidad política y económica del gobierno nacional (Frankenberger y Goldstein 1992:85).

Para una familia, la disponibilidad de al imentos depende de muchas variables. Entre éstas están la producción de alimentos (incluyendo la destinada al consumo, para semillas, forrajes y mermas), la tierra, el trabajo, el capital, el conocimiento y la tecnología, en las relaciones de producción; los precios de los alimentos, el abasto de alimentos y el mercado; el flujo monetario por ingresos de renta de la tierra, salarios, utilidades de las empresas o venta de activos, deudas y otras disponibilidades; reservas netas y recepciones netas en especie, renta y salarios, donaciones, crédito y transferencias gubernamentales y otros donadores internos y externos. Claramente un movimiento adverso en alguna o algunas de estas variables afectará la seguridad alimentaria de las familias.

Si tales movimientos adversos son temporales y fallan las estrategias famliares para hacer frente a la situación, entonces se presenta un caso transitorio de inseguridad alimentaria. Pero si tales movimientos provienen de problemas estructurales y continúan durante largo periodo, 
entonces la situación de inseguridad al imentaria se convierte en crónica (Alamgir y Arora 1991:7).

En comunidades marcadas por la tenencia de la tierra y la distribución equitativa del ingreso, las respuestas de las familias a la inseguridad alimentaria no son las mismas. Además, idénticas condiciones climatológicas pueden afectar a las familias de variados niveles económicos, de diferentes grados. Las condiciones que producen déficits estacionales para algunas familias significan hambre y miseria para otras. Las familias más pobres, al tener menos bienes y una base de recursos más débil, son más vulnerables al presentarse una situación de emergencia general que las familias más ricas, y comienzan a sufrir más pronto cuando gol pean los déficits alimentarios. Los pobres recurren muy pronto a la venta de sus inventarios alimenticios, empeñar sus tierras, a incurrir en deudas, a vender su trabajo y a conseguir grano a tasas de interés altas. En esencia, el fracaso en las cosechas revela, más bien que una causa, la frágil natural eza de la seguridad alimentaria entre las familias rurales vulnerables. Al mismo tiempo, las familias prósperas compran sus existencias a precios deflactados en condiciones de sobreproducción, venden o prestan grano a los agricultores necesitados, adquieren trabajo asalariado a tasas deprimi das y compran tierra. Así, durante la crisis alimentaria, el círculo de la acumulación y la descapitalización puede ocurrir simultáneamente dentro de una comunidad simple (Frankerberg y Goldstein 1992:87).

Y en última instancia, la seguridad alimentaria comienza y termina en la familia: ambas, producción y consumo de alimentos tiene lugar a nivel familiar. No importa quétan extensa o efectiva sea la intervención estatal en el sector de alimentos, a final de cuentas, las consecuencias de un sistema alimentario recae sobre los ciudadanos y sus familias. Una situación dada de seguridad alimentaria nacional es la sumatoria de las perspectivas de cada familia.

Las unidades familiares tienen su propia perspectiva de la seguridad alimentaria. Dicha perspectiva depende, por una parte, de la información y la experiencia cotidianas y de las señales del mercado y, por otra, del nivel de ingreso económico. Estos elementos son articulados por las familias con la disponibilidad y los costos de los nutrientes. 


\section{Seguridad Alimentaria y Medio Ambiente}

Los ambientalistas consideran que la seguridad alimentaria a largo plazo, en cualquiera de los niveles mundial, nacional, familiar, depende de la conservación de los recursos naturales, y ponen énfasis en señalar el deterioro del agua, del aire y del suelo, así como la extinción de numerosas especies animales.

Una de las causas del deterioro de los suel os (además de la contaminación industrial y del abuso en la utilización de productos tóxicos en la agricultura) está en la inseguridad alimentaria de 930 millones de pobres de los países subdesarrollados que no saben dónde van a encontrar su próximo alimento y que, comprensivamente, ponen las ventajas de corto por encima de consideraciones de impacto al medio ambiente, en sus desesperados intentos por alimentarse (Yamamori 1992).

No obstante la relación tan estrecha entre seguridad alimentaria y medio ambiente, la formulación de políticas para la seguridad alimentaria familiar y la sustentabilidad ambiental han ido por caminos paralelos. Relacionar estos dos factores ha sido difícil, en parte porque, en su mayoría, el trabajo rel evante sobre estos aspectos ha sido realizado por disciplinas y áreas de investigación diversas, donde las interacciones entre la seguridad alimentaria y el aspecto del medio ambiente raramente se correlacionan. Una excepción donde se ha dado la convergencia entre seguridad alimentaria y medio ambiente ha sido a través de la atención a grupos vulnerables que han experimentado restricciones alimentarias durante las sequías (Frankenberger y Goldstein 1992:85).

\section{Propuestas de solución a la inseguridad alimentaria}

Las causas de la inseguridad alimentaria son múltiples, y múltiples son la medidas para eliminarlas, dadas las diferencias en las condiciones reales de un país y de una región, y a la necesidad de enfatizar en aspectos y dinámicas particulares.

La falta de confianza generalizada en la economía, la guerra y los errores gubernamentales, son factores fundamentales que alimentan el 
proceso de inseguridad alimentaria.

Las propuestas de acción para hacer frente a la inseguridad alimentaria son muy variadas. Van desde las sugerencias de apoyarse totalmente en los mercados internacionales, hasta los Ilamados a la autosuficiencia productiva. Lo débil del primer argumento radica en que los mercados internacionales no reflejan los precios reales, la modificación de la estructura de las importaciones es un proceso largo y que el mantenimiento de reservas estratégicas reducidas implica peligros serios de desabasto por falta de oportunidad con que podrían llegar los alimentos del exterior para hacer frente a una emergencia, si es que se dispone de los recursos para adquirirlos.

Apoyarse en las donaciones de los países superavitarios resulta riesgoso para la seguridad alimentaria, además del costo político que implica la recepción de la ayuda alimentaria. También es de sobra conocido que, en los años en que los precios mundiales son altos, debido a la disminución de las reservas internacionales, algunos países donantes destinan a los mercados comerciales los alimentos concesionados que en tiempos normales destinan a los países deficitarios, con lo que agravan más la situación de éstos.

Por las razones anteriores, los radicales de la autosuficiencia en materia de alimentos afirman que cada país debe crear sus propios sistemas de seguridad alimentaria nacional para no depender en absoluto de las importaciones de alimentos, sin importar los costos económicos. Sin embargo, la autosuficiencia en términos absolutos es imposible. $Y$ es un hecho que los mercados internacionales, aunque imperfectos, existen: en el caso de los cereales, alrededor del 12\% de la producción mundial -225 millones de toneladas en 1990- se destina al comercio exterior (Siamwalla y Valdés 1991:236).

La opinión de los organismos internacionales, como la FAO, sobre la que difícilmente alguien podría estar en desacuerdo, es que el reforzamiento de la seguridad alimentaria comienza por el nivel nacional y todos los países pueden contribuir a este esfuerzo. A esto habría que agregar que la acción gubernamental puede aumentar, pero también disminuir, las oportunidades de lograr la seguridad alimentaria.

La causa primaria de la inseguridad alimentaria, sin contar los casos 
de emergencia -guerras y calamidades naturales- es la insuficiente producción de alimentos. De ahí que la mejor forma de reforzar la seguridad alimentaria sea mediante la producción interna, especialmente de productos básicos. El comercio puede ayudar a cubrir faltantes de un país, siempre y cuando exista una situación general (mundial) de relativa estabilidad. En situaciones de emergencia -real o ficticia- éste no ha operado: hay periodos, como el de 1973-1974, en los que resulta imposible obtener los productos que se necesitan a ningún precio. En consecuencia, sólo el control de la producción puede crear las bases sólidas para la seguridad. Aunque hay que reconocer que la disponibilidad de alimentos no es condición indispensable para lograr la seguridad alimentaria (Barracloughj 1991:2).

Por el lado de la producción, dadas las limitadas posibilidades de ampliar la frontera agrícola natural para la mayoría de los países, el aumento en la disponibilidad de alimentos se logra vía el incremento de la productividad. Otra condición necesaria para solucionar el problema de la inseguridad alimentaria es la mejoría de los sistemas de distribución que implican grandes inversiones en infraestructura de almacenamiento, comunicaciones y transportes. Los sistemas de alarma oportuna y políticas claras sobre existencias y comercio, que permitan compensar los déficits de unas regiones con los superávits de otras, son condiciones que requiere la seguridad alimentaria.

Entre las acciones gubernamental es básicas que se requieren para hacer frente a las emergencias provocadas por efectos de la naturaleza o del hombre se cuentan: a) mantenimiento de existencias adecuadas de alimentos básicos; b)conformación de un sistema de subsidios que, sin distorsionar la relación costo-precio, permita el sostenimiento de una estructura global de distribución de alimentos y el suministro inmediato de mercancías a zonas con emergencias alimentarias; c) establecimiento de una estructura de precios que defienda a las familias (en especial a las de escasos recursos) de los impactos negativos de los mercados externo y nacional. Los objetivos básicos de un sistema de precios consisten en cubrir las necesidades mínimas, mientras se asegura el crecimiento sostenido de la producción. Para que esto último se dé, los precios tendrán que ser suficientes para cubrir los costos de producción, 
de distribución y de riesgo, en todas las etapas de la cadena al imentaria.

Al problema de adquisición de alimentos por parte de los países deficitarios hay que agregar, en algunos casos, la falta de una adecuada infraestructura regional para hacer llegar los productos a poblaciones relativamente aisladas. Esto representa para muchos países, altos costos financieros y de transporte. En consecuencia, la estabilización de precios en las regiones más aisladas, donde los niveles de consumo son superiores a la producción, requieren de apoyos especiales de los gobiernos. Otras condiciones para reforzar la seguridad alimentaria regional, además del mejoramiento de los sistemas de distribución -que requieren grandes inversiones en infraestructura de comunicaciones y transportes- es el establecimiento de sistemas oportunos de alarma y políticas claras sobre existencias y comercio, que permitan compensar los déficits de unas regiones con los superávits de otras.

A nivel familiar, el hambre tiene una estrecha relación con la pobreza. Por consiguiente, la generación de ingresos a través de la creación eficiente de empleos es un componente importante de toda estrategia concebida para mejorar la seguridad alimentaria de la unidad familiar. El que esa creación de empleo conduzca a una mayor seguridad alimentaria obviamente no es sól o cuestión de suministros de alimentos, sino que más bien depende de la rentabilidad social de incrementar esos suministros provenientes de la producción interna (Timmer et. al. 1985:157).

Las fluctuaciones en la producción (independientemente de si éstas se producen en el sector alimentario) y en los precios de los alimentos y/ o otros productos, agravan la inseguridad alimentaria de las familias. Dichas fluctuaciones conducen directamente a variaciones en los ingresos reales que percibe la comunidad y pueden afectar de distintas maneras a diferentes miembros de la comunidad. De lo anterior se deduce que el suavizar las fluctuaciones de los ingresos reales contribuye a reforzar la seguridad alimentaria (Siamwalla y Valdés 1991:236).

A nivel familiar es requisito de la seguridad alimentaria la disponibilidad y el acceso estable a los alimentos (producidos o adquiridos), sin que ello conduzca a la degradación del medio ambiente.

Las consideraciones anteriores son aspectos parciales de la seguridad 
alimentaria, cuya resolución por sí misma no resuelve el problema, como tampoco lo resuelven las apreciaciones convencionales. Decir que el hambre es causada por el rápido crecimiento de la población, la insuficiente disponibilidad de recursos naturales -tierra y agua-, desastres climatológicos, ignorancia campesina, uso de tecnologías atrasadas, lento crecimiento económico o gasto innecesario en armamentos y bienes suntuosos implica que, el iminando al guno o varios de estos factores, se resolvería el problema, y esto no es así (Barraclugh 1991:4).

La seguridad alimentaria depende de políticas adecuadas que estimulen la producción y eleven el ingreso familiar, pero también de manera especial, de la existencia de instituciones socioeconómicas y políticas que aseguren el acceso a los recursos productivos, el empleo y los servicios social es y que valoren el ecosistema natural para una futura productividad; requiere de políticas que den una alta prioridad a la eliminación del hambre. Todo ello requiere de una voluntad política porque, en última instancia, la seguridad alimentaria es un problema político.

\section{La seguridad alimentaria en Asia}

La preocupación de los países asiáticos por la seguridad alimentaria es una constante histórica. En los últimos años, al margen de la claridad con que se ha manejado el concepto, en la práctica se percibe, de los gobiernos del área, una preocupación por eliminar las trabas estructurales que impiden el desarrollo económico y el aumento de la producción agrícola.

Aquí se presentan dos casos: el de J apón, que ha logrado aumentar sustancialmente la producción agrícola y el nivel de ingreso de los agricultores. No obstante los bajos niveles de autosuficiencia en varios productos básicos de este país, la seguridad alimentaria y el nivel nutricional de las familias son de los más altos del mundo.

Y el caso de China que, a través de profundas reformas a su sistema de producción, ha al canzado volúmenes sin precedentes en la producción agrícola, lo que le ha permitido mantener una balanza agrícola equilibrada. J unto con el estímulo a la producción y la paulatina elevación del 
ingreso campesino, está desmantel ando su estructura de distribución igualitaria con la consiguiente polarización en los niveles de ingreso de las familias.

\section{Japón}

En el caso de J apón encontramos la paradoja de un país que dispone de un al to nivel de seguridad alimentaria familiar a la par de una creciente disminución de la autosuficiencia en la producción de alimentos. E I elevado poder adquisitivo de la población y su eficiente red de distribución permite cubrir la demanda de los consumidores con una el evada

\section{Consumo y producción de cereales en países seleccionados de la C uenca del Pacífico, 1990. ( 1,000 toneladas métricas)}

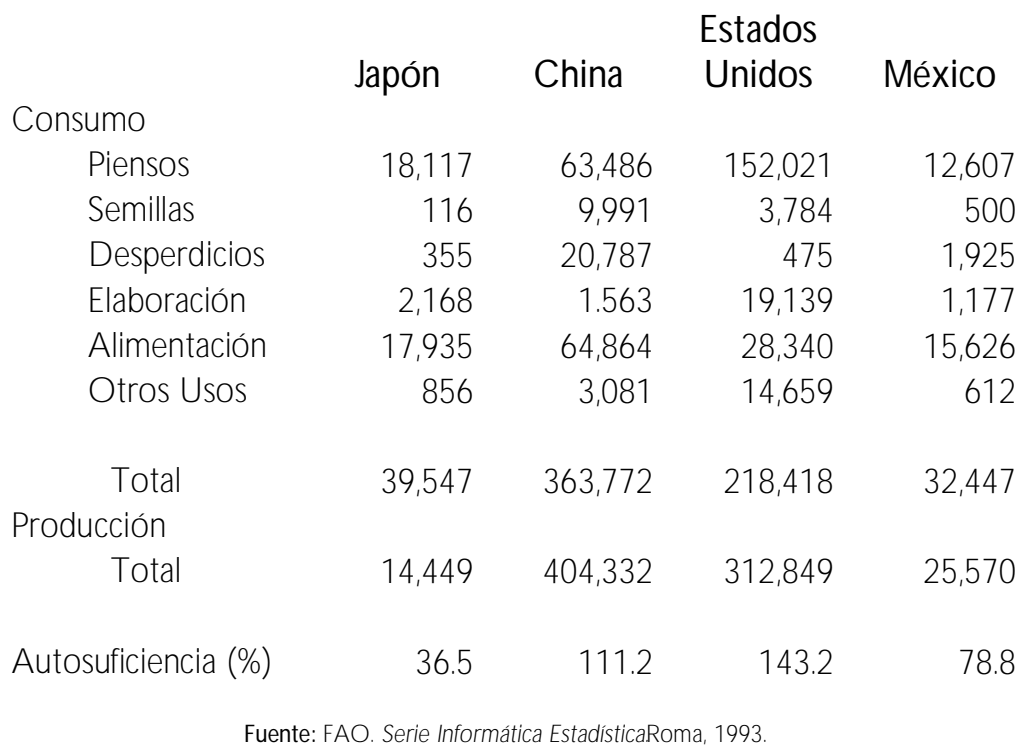

2 En términos absolutos, el valor de las importaciones de productos agropecuarios de Japón se ha multiplicado por más de nueve veces en los últimos veinte años: de 3.2 mil millones de dólares, en 1970, pasó a más de 28.7 mil millones en 1990.

A unque en relación con el total de las importaciones, las compras de productos agrícolas disminuyeron ligeramente de $17.2 \%$ a $12.2 \%$ en el mismo periodo. (Cuadro N o.4). 
proporción de productos del exterior. ${ }^{2}$

J apón produce al rededor del $75 \%$ de sus requerimientos de fruta, carne y productos lácteos, y es autosuficiente en más de $90 \%$ en arroz (100\%), papas, vegetales, huevos, productos marinos, azúcar, grasas, aceites y salsa de soya. La tasa de autosuficiencia alimentaria, considerada sobre la base calórica, es de las más bajas entre los países industrializados: 47\% en 1990 (Falk 1994:332).

La producción y el consumo de cereales dan una idea de la autosuficiencia alimentaria de J apón y su relación con la de otros países, como se muestra en el cuadro 2.

Desde la óptica japonesa tradicional, la seguridad alimentaria es sinónimo de autosuficiencia y consiste en producir internamente los requerimientos mínimos alimentarios que requiere su población. Su fundamento es que la seguridad alimentaria sól o puede mantenerse si se dispone de la capacidad para producir los granos y otros cultivos básicos necesarios para asegurar un mínimo de nutrición, suponiendo que el país viera cortadas sus rutas de acceso a los mercados externos.

EI deseo de ser autosuficiente en la producción de alimentos está profundamente enraizado en el pueblo japonés. Esta actitud se fundamenta en su experiencia histórica y en la conciencia que se tiene de las limitaciones del país en cuanto a dotación de recursos naturales.

En los últimos cien años, la atención que J apón ha puesto a la seguridad alimentaria ha variado en intensidad. Ésta ha dependido de su correlación con los mercados externos de alimentos, en especial de granos básicos. Los periodos en que J apón ha intentado la total autosuficiencia alimentaria corresponden a los tiempos en que las perspectivas de crisis mundiales de alimentos ponían en peligro los surtimientos del exterior (Sanderson 1978:58).

En los sesenta, la agricultura japonesa progresivamente se integró a la división internacional del trabajo. En correspondencia al cambio en las ventajas comparativas de la manufactura, las tasas de autosuficiencia al imentaria en al imentos básicos y otros productos agrícolas dedinaron en cuanto a la autosuficiencia para las cosechas de cereales de invierno (trigo y cebada) y frijol de soya. Los esfuerzos de incrementar la producción interna fueron debilitados a finales de los sesenta, bajo la 
presión del superávit de arroz, así como de las perspectivas optimistas de los abastos mundiales de alimentos debido a la difusión de la "revolución verde en Asia" (Hayami 1975:78).

Las opiniones sobre una mayor integración a la división internacional del trabajo casi desaparecieron a principios de los setenta, cuando se dio la disminución en las cosechas mundiales de alimentos y los consiguientes incrementos de los precios. En este tiempo, una vez más la autosuficiencia comenzó a ser un slogan político muy popular. Este sentimiento fue reforzado también por los elevados precios de los energéticos de esa época.

Al margen del atractivo emocional de la autosuficiencia, es importante para el bienestar nacional, tanto como por seguridad, mantener e incrementar la capacidad de producción agrícola, mientras se mejorara la eficiencia productiva. Una importante consideración debe ser la promoción de la eficiencia económica sin causar tensión innecesaria en la estabilidad social por la despoblación rural y el congestionamiento urbano (Hayami 1975:78).

Recientemente, la disminución en el énfasis por lograr a toda costa la autosuficiencia alimentaria parte de la experiencia de que la producción mundial de alimentos es superior a la capacidad del mercado para absorberlos, lo que da la sensación de que existe una producción superavitaria.

Ante la imposibilidad de producir internamente los requerimientos nutricionales mínimos que requiere su población, y dado el incremento de la demanda alimentaria, J apón sólo tiene la opción de ampliar su margen de seguridad alimentaria diversificando sus fuentes de abastecimiento. La tendencia parece ser surtirse de al imentos pecuarios y de consumo humano a través de acuerdos con otros países, complementados con inversiones en desarrollos agropecuarios en el exterior que le permita reforzar los compromisos de venta de los países superavitarios. Así, la paradoja es que la consolidación de la seguridad alimentaria de J apón tiene una estrecha relación con el desarrollo agrícola del exterior y con esquemas más seguros de importación de alimentos.

Ante la tendencia hacia la integración agrícola mundial, el reto inmediato para la agricultura japonesa es lograr un mayor rendimiento por yen invertido o una disminución de los costos en las ramas de la 
producción agrícola que sea factible mantener operando, con el fin de no incrementar su dependencia alimentaria relativa del exterior. En J apón, la productividad de la tierra es muy alta, mientras que la productividad por unidad de trabajo y capital es baja, situación contraria a la que se presenta en otros países con mayor dotación de recursos naturales, como Estados Unidos.

\section{China}

Conocida por mucho tiempo como la tierra del hambre, desde 1949 China no ha vuelto a presentar problemas serios de hambre -quizá con excepción de un corto periodo entre finales de los cincuenta y principios de los ochenta. Por el contrario, el acceso a una adecuada alimentación en la mayor parte del territorio chino ha ido en constante aumento.

En los primeros años del acceso al poder del Partido Comunista se obtuvo un avance importante en la seguridad alimentaria. Esto se dio como resultado de una radical y rápida reforma agraria. La movilización de los campesinos sin tierra y de los pequeños propietarios para expropiar y repartir equitativamente las propiedades de los terratenientes y de los agricultores ricos. Después de la Reforma Agraria, casi todos Ios residentes del campo tuvieron acceso a la tierra suficiente para hacer frente a la mayor parte sus necesidades de alimentación (Barraclough 1991:53).

A partir de esta estructura de la tenencia de la tierra se dieron, durante los cincuenta y sesenta, los esfuerzos por organizar la producción en el campo de forma colectiva y, a partir de finales de los setenta, la descol ectivización.

En China, el concepto de seguridad alimentaria como tal no se ha manejado. En cambio, la noción de autosuficiencia alimentaria, en especial de granos básicos, fue parte sustancial de la política agrícola en un contexto general de seguridad nacional. La política de autosuficiencia alimentaria corresponde a los periodos en que los sectores izquierdistas impusieron sus puntos de vista y determinaron las acciones de política agrícola.

Un objetivo central de las políticas agrícolas de los primeros treinta 
años de la República Popular era la redistribución igualitaria de los bienes básicos, que tenían una relación directa con la eliminación de las evidentes disparidades en el consumo y con el reforzamiento de la seguridad alimentaria de las familias. En el campo, cada miembro del equipo de producción tenía derecho a una ración básica de granos conocida como el "tazón de hierro". En las ciudades, el racionamiento y la venta de estos productos a precios muy bajos aseguraba una distribución equitativa. En ambos casos, la burocracia estatal Ilevaba un detallado control de la adquisición y abasto de los productos.

Dado que, tanto en el campo como en la ciudad los granos aportan más del $80 \%$ de las necesidades de calorías, su control y desponibilidad tenía como objetivo asegurar el abasto de los requerimientos mínimos y la igual dad en la distribución.

Por otra parte, el presidente Mao estimuló los esfuerzos por lograr la autosuficiencia al imentaria a los niveles nacional y regional. Una razón importante era su correlación con el funcionamiento de las comunas populares.

La política de autosuficiencia fue también parte de una amplia estrategia de defensa nacional. La estrategia de autosuficiencia regional de Mao, de los cincuenta a los setenta, fue en gran parte inspirada en consideraciones militares. Con tal política China podía perder territorio al ser invadida por ejércitos enemigos desde el norte y el sur sin sufrir grandes disrupciones en el resto de la economía (Staatz 1991:19). El concepto de autosuficiencia local y regional era un elemento de estrategia militar sobre una guerra de desgaste en la que las fuerzas regionales autosuficientes tendrían un papel preponderante. Especialmente en los sesenta, los líderes chinos estaban muy preocupados por la posibilidad de una ampliación de la guerra del sudeste asiático hacia el territorio chino o la invasión soviética del norte del territorio. De ahí la meta de crear regiones que pudieran sobrevivir al aislamiento (Fan 1991:43).

Otras consideraciones de esta política de autosuficiencia alimentaria fueron, por una parte, el reflejo de la oposición hacia el comercio que mantuvieron los sectores más izquierdistas dentro del Partido Comunista de China, así como un reconocimiento del bajo desarrollo en la infraestructura de transporte interno (Lardy 1984). 
A finales del decenio de los setenta, una vez suprimida la corriente izquierdista, el marco institucional en el que se desarrol ló la agricultura china volvió a definirse sobre la base del pragmatismo aplicado a principios de los sesenta, después del Gran Salto Adelante y antes de la Revolución Cultural. Los nuevos lineamientos, que fueron definiéndose después de 1977 y comenzaron a aplicarse a partir de 1979.

En la actualidad, como resultado de los cambios institucionales, la política de autosuficiencia alimentaria a cualquier costo ha sido substituida por la búsqueda de una mayor productividad, sobre la base de aprovechar las ventajas comparativas y la especialización regional (Senggen 1991:266).

Con el cambio en la política agrícola, realizado a partir de 1979, se restauraron las condiciones de producción especializada y de ampliación de los intercambios interregionales de productos agrícolas que habían sido abolidas desde mediados de los años sesenta, cuando se conformaron las comunas populares y se dio inicio a la Revolución Cultural. Durante la Revolución Cultural, igual que el periodo del Gran Salto Adelante, la autosuficiencia regional y local se estableció como el objetivo fundamental de la política agrícola (Lardy 1985:33).

La autosuficiencia en la producción de granos, por la cual se pretendía que cada región produjera los granos que requería, ha sido abandonada. Ahora, a los agricultores, en cada región, se les permite especializarse en el cultivo de los productos que más se adecuen a su tierra, al tipo de precipitación pluvial de la zona, a la temperatura y a otras características del medio ambiente (McMillan 1988:5).

La nueva política agrícola representa un viraje de ciento ochenta grados en la tendencia seguida desde los años cincuenta: la descentralización y el abandono de los controles estatales directos sobre las unidades de producción marcan la pauta de estos cambios. El eje de la nueva forma de operación fue el establecimiento, desde 1978, de un sistema contractual mediante el cual se reformó la estructura de los incentivos rurales y se estimuló el establecimiento de una amplia variedad de técnicas organizacionales y administrativas para interrelacionar el ingreso monetario de los productores con la cantidad y calidad de los bienes producidos (Zweig 1985:141). Con el nuevo sistema, la 
mayoría de los aspectos de la administración colectiva, como los puntos de trabajo, las raciones y la distribución, fueron abandonados. Aunque en términos formales la tierra continúa siendo de propiedad colectiva, ya para 1983 más del $90 \%$ de las familias campesinas operaban bajo el sistema contractual (McMillan et.al. 1988:4; Lardy 1986-1; Lardy 19862; Watson 1984; Crook 1985).

La nueva estrategia alimentaria se fundamenta en las unidades familiares de producción agrícola, el retorno de las parcelas privadas y la vuelta al mercado después del casi total control estatal. La eliminación de la distribución colectiva hacia el interior de los equipos de producción significa que la ración básica ya no se distribuye automáticamente a las familias.

Por otra parte, el esfuerzo de lograr la autosuficiencia en la producción de alimentos, en especial de granos básicos, se realiza a través de las señales que el Estado manda al mercado a través del manejo de los precios relativos de los productos. Otra opción para resolver el problema de ajustar la oferta a la demanda de granos consiste en persuadir a la población de modificar sus hábitos de consumo de carne para evitar que la demanda de proteína animal se incremente por los tipos de ganadería que requieren del uso intensivo de granos (Dixit y Shwu-Eng 1991).

Esfuerzos por evaluar los resultados concretos de los ajustes estructurales han sido realizados recientemente. Lin (1987) atribuye el rápido crecimiento en la producción agrícola, entre 1980 y 1984, al sistema de responsabilidad por contrato con base en la familia. Lin encontró que el $20 \%$ en el aumento de la productividad, o el $60 \%$ del crecimiento en la producción agrícola, se debió al cambio institucional. McMillan (1988), al correlacionar la importancia relativa del incremento en los precios de los productos agrícolas y la introducción del sistema de responsabilidad, concluye que el $22 \%$ del incremento en la productividad de la agricultura china se debió a precios más altos y el 78\% a cambios en el esquema de incentivos. Fan Senggen (1991) agregó al factor del cambio institucional el relativo a los efectos del cambio tecnológico, y concluyó que el crecimiento total de los insumos explica en $57.7 \%$ el crecimiento total de la producción y los avances del cambio tecnológico y el mejoramiento de la eficiencia el restante $42.3 \%$. Dentro de este esquema, el cambio 
institucional contribuyó con el $26.6 \%$ del crecimiento de la producción.

No obstante las diferencias cuantitativas y los diferentes métodos de evaluación utilizados, existe consenso de que el cambio institucional, que dio mayor autonomía y responsabilidad a las unidades familiares agrícolas, contribuyó de manera muy significativa a incrementar la produccion agrícola de China.

\section{América}

Para esta región se toman dos casos representativos: el de Estados Unidos, considerado el granero del mundo, con una agricultura altamente productiva y bien planificada, y con un sistema de seguridad social que le permite amortiguar las manifestaciones extremas de la pobreza. Y el de México, país deficitario en alimentos básicos pero con una balanza agrícola nivelada. Con graves problemas de inseguridad al imentaria familiar, que busca desde hace más de un decenio aumentar su capacidad de producción.

El concepto de seguridad alimentaria presenta también marcadas asimetrías entre ambos países; tanto por lo que respecta a su desarrol lo, como a la forma de plantearlo y aplicarlo.

\section{Estados Unidos}

La seguridad alimentaria, en su sentido más amplio, forma parte de las políticas agrícolas y alimentarias de Estados Unidos desde principios de los años treinta. Aunque las bases del desarrollo agrícola ya se habían completado desde finales del siglo pasado y principios del presente con el impulso a la educación, la investigación y el extensionismo.

La Gran Depresión de 1929 a $1933^{3}$ había puesto en evidencia la

3 Hayami y Ruttan (1989:410) y Barnes (1987:823) describen el panorama agrícola de Estados U nidos de 1932 en los siguientes términos: el valor total de la renta agrícola en ese año era del 34.6\% en relación con el de 1919: había disminuido de quince mil a 5,200 millones de dólares. la proporción de la renta agrícola, en relación con la total de la nación, bajó del 18.5\% en 1919-1929, a diez por ciento en 1932. En este mismo año, el precio de los productos agrícolas era de sólo el $52 \%$ al prevaleciente antes de la Primera Guerra Mundial, mientras que los insumos para los agricultores se habían elevado en diez por ciento. Como consecuencia de esto, el valor de la propiedad agrícola disminuyó drásticamente mientras que, por otro lado, las hipotecas y los remates por falta de pago se aumentaron en forma alarmante. 
inoperancia del liberalismo. La respuesta de E.U. fue el establecimiento de una política keynesiana en la que el Estado cumple un activo papel regulador de la actividad económica. En esta época fue cuando se comenzó a conformar la estructura de planeación del sector primario; entonces surgieron los precios de garantía, las cuotas de producción y los arancel es como aspectos determinantes de su política agrícola. Éstos habían sido diseñados original mente como medidas de emergencia para evitar el colapso de los ingresos de los productores del campo por efecto de la rápida contracción de la demanda frente a la oferta inelástica de productos agrícolas durante la depresión.

Durante el "N ew Deal", el congreso aprobó un importante número de leyes crediticias para rescatar al agricultor norteamericano, las que de hecho conformaron el sistema de planeación agrícola de Estados Unidos. $^{4}$

Uno de los objetivos principales de la estructura de planeación agrícola de E.U. fue adaptar la oferta a la demanda de bienes agrícolas. Desde entonces, a través del Departamento de Agricultura, se han instrumentado y aplicado los programas de apoyo a los precios y el control de la producción, a fin de estabilizar el ingreso de los agricultores.

El carácter regulatorio de la política agrícola se centra en hacer que el sistema económico opere más efi cientemente, protegiéndolo de las externalidades y/o previniéndolo de los abusos del mercado (Hallberg 1992:16). Hay que recordar que la producción de cereales de Estados Unidos tradicionalmente supera con mucho el consumo interno. Por ejemplo, en el decenio pasado, el promedio anual en la producción de cereales fue superior a los 292 millones de toneladas, de las cuales exportó 9.3 millones al año, equivalentes al 32.6\% de su producción cerealera (FAO 1993).

Así, por el lado de la producción, el principal problema de la agricultura de Estados Unidos es el excedente: el qué hacer con su producción

4 Cabe resaltar la A gricultural Adjustment A del 12 de mayo de 1932, que extendía el crédito; la Federal Farm Loan Acte 1916; la Farm Credit A ctel 16 de junio de 1933; la Farm Mortgage Refinancing Actlel 31 de enero de 1934, la Crop Loan Actlel 23 de febrero de 1934; la Farm Mortgage Foreclosure A del 28 de junio de 1934; la Agricultural Adjustment A del 12 de mayo de 1933 , que tenía por objeto controlar el exceso de oferta de productos como trigo, algo dón y cerdo. Leyes y enmiendas posteriores pusieron bajo el control de la A gricultural Adjustment A at ganado productor de leche y carne, al centeno, la cebada, el cáñamo, el sorgo, la remolacha azucarera, la caña de azúcar y el cacahuate (Hallberg 1992; Barnes 1987:826). 
superavitaria y cómo restringirla sin distorsionar la distribución de las rentas. Esto es, cómo establecer mecanismos para que los estímulos al retiro de superficies cultivables de la producción llegue a los agricultores que más lo necesitan y evitar que el contribuyente y el consumidor paguen más de justos por estos productos. En este sentido, la legislación agrícola contiene lineamientos específicos para estimular al productor y controlar la oferta comercializable. Entre éstos se cuentan los precios de apoyo y varios esquemas para respaldar directamente el ingreso de los agricultores como pagos por deficiencia, precios objetivo, préstamos para comercialización, pagos por desastre, certificados genéricos, etcétera (Glaser 1986; Hallberg 1992:26).

La mayor parte de la legislación agrícola de Estados U nidos establece explícitamente que uno de sus objetivos es mantener un adecuado abasto de alimentos genuinos y saludables a precios razonables (Hall lberg 1992:66). Esta idea se ha convertido, para muchos países, en políticas expresas de seguridad o autosuficiencia alimentarias. Sin embargo, en un país como Estados Unidos, donde no existe un sentido de escasez de alimentos ni ha pasado por experiencias traumáticas de falta de comida -como es el caso de países con menos recursos o con guerras recientes en sus territorios- el concepto de seguridad alimentaria está poco desarroIlado.

La Ley de Seguridad Alimentaria de 1985, aunque introduce y reajusta algunos mecanismos de apoyo a la producción agrícola (tal como lo harían otras leyes aprobadas posteriormente, entre las que se cuenta la Ley Alimentaria, Agrícola, de Conservación y Comercio de 1990), no modifica sustancialmente la estructura de planeación y control. En cuanto a la seguridad alimentaria, este ordenamiento no establece definiciones doctrinarias ni pretende desarrollar el concepto. De manera directa y pragmática establece sus objetivos. Dice el documento: (es) "un acta para extender y revisar los apoyos de precios agrícolas y programas relacionados, prever la exportación agrícola, conservación de recursos, crédito al campo e investigación agrícola y programas relacionados, continuar la asistencia alimentaria a las personas de bajos ingresos, asegurar a los consumidores una abundancia de alimentos y fibras a precios razonables, y para otros propósitos" (Food Security Act 
of 1985, p.1354).

En este sentido, la Ley establece un marco legal para regular la producción de los bienes agropecuarios básicos (lácteos, lana y angora, trigo, forrajes, algodón, arroz, cacahuate, frijol de soya y azúcar), el comercio interior y exterior, la conservación, el crédito, la investigación, extensión y enseñanza, la distribución de alimentos a través de programas de asistencia social y la mercadotecnia entre otros (FSA 1985 pp.1354-1362).

Ante la falta de una política expresa de seguridad alimentaria, los fundamentos de ésta hay que buscarlos en la aplicación de la política y no en el discurso.

Sobresalen, dentro de los lineamientos de política agrícola, el carácter gl obalizador de la apreciación de Estados Unidos sobre la alimentación. En este sentido, la preocupación mundial estadounidense abarca tanto los aspectos de la producción de alimentos como los de la distribución, en especial cuando algunas zonas del planeta son afectadas por los elementos incontrolables de la naturaleza, que se reflejan en la baja disponibilidad de alimentos de algunos países y en las consecuentes hambrunas.

Con este objeto, E.U. realiza un detallado monitoreo sobre el desarroIlo de la agricultura mundial, tanto por lo que se refiere a la evaluación de las cosechas, como del nivel de deterioro del medio ambiente. A través de los sistemas de satélites de observación, que complementa con trabajos de campo, obtiene una adecuada información sobre la seguridad alimentaria mundial (SatelliteTechnology and World Food Security, Select Committee on Hunger, U.S. House of Representatives, U.S. Government Printing Office, Washington, 1989).

Por otra parte, participa en el abastecimiento de alimentos a precios subsidiados o mediante donaciones para los países subdesarrollados con problemas alimentarios. La propia Ley de Seguridad Alimentaria tipifica las condiciones, las formas y los montos con los que el gobierno estadounidense interviene para apoyar en casos extraordinarios y no extraordinarios a los países pobres.

La Seguridad Alimentaria Familiar.- En el contexto de la abundancia y de los excesos en el consumo de alimentos existen problemas de 
subconsumo de nutrientes. Al respecto, Allen y Sach (1993:145) presentan una síntesis de organismos y autores que han tratado esta situación: diez millones de estadounidenses no tienen acceso regular a una al imentación suficiente; las mujeres, los niños y los viejos son los que están en mayor riesgo de hambre; $76 \%$ de los hambrientos en Estados Unidos son gente de color. En California, el estado más rico del país, 1.4 millones de niños están hambrientos o en riesgo de hambre. Una ironía muy particular es que muchos de los hambrientos en Estados Unidos son aquéllos que cosechan y procesan la abundancia alimentaria.

Por su parte, K. Clancy (1993:255) presenta el siguiente panorama sobre las razones directas de la subalimentación, basado en estudios de Ios Departamentos de Comercio y de Salud y Servicios Humanos: aproximadamente 33.5 millones de personas, o el $13.5 \%$ de la población de Estados Unidos, son consideradas oficialmente como pobres; definida la pobreza como un ingreso anual de menos de \$13,400 dólares para una familia de cuatro miembros. Otro cinco por ciento está cerca de la pobreza, con ingresos entre 100 y 125\% de la pobreza. Aproximadamente el $40 \%$ de las familias pobres en Estados Unidos ("Ios más pobres de los pobres") tienen ingresos de menos de $50 \%$ del nivel de pobreza. Este porcentaje es del doble del que era en los sesenta y setenta, y uno de los signos más obvios de la amplia disparidad entre ricos y pobres.

Estados Unidos tiene una tasa de pobreza mucho más alta que la de otros países desarrollados con los cuales es frecuentemente comparado -Canadá, Australia, Francia y otros países similares. La incidencia de hambre en esos países es también menor debido a que los beneficios de la asistencia social induyen pensiones adecuadas para alimentos.

Volviendo sobre la política agrícola de Estados Unidos encontramos que, desde los años treinta, ésta se ha adaptado a las diferentes condiciones de los entornos económico y político, nacional e internacional. De este modo se ajusta a las condiciones de paz y de guerra y a los objetivos de gobiernos demócratas -más proteccionistas- y republicanos -más liberales. Pero no obstante las variantes en la política agrícola, los gobiernos en turno no han perdido de vista la condición básica que toda actividad productiva empresarial debe tener: la obtención de una utilidad. Esta Ley, por ejemplo, aprobada por un Congreso mayoritariamen- 
te demócrata, fija lineamientos claros que debió llevar a la práctica la administración republicana; entre éstos está el de reducir el riesgo que trae aparejada la variación de los precios de los productos agrícolas básicos y los altibajos de la producción. Con los esquemas de estabilización de precios y el seguro agrícola, los agricultores enfrentan los caprichos de los ambientes físico y económico. Por el lado del consumo, al margen del mercado, incluye modificaciones de carácter operativo para programas de asistencia social tipificados en el Food Stamp Act y en otros instrumentos legal es como el Social Security Act y laTemporary E mergency Food Assistance Act. Detrás del debate sobre la política agrícola de E. U. están los puntos de vista encontrados de líneas políticas claramente identificadas con keynesianismo disfrazado de liberalismo y de un liberalismo a ultranza. La definición de las políticas y su concreción en leyes no sólo se refleja en la situación alimentaria de ese país, sino en la del resto del mundo, dada su participación en el comercio y la producción agrícola global.

\section{México}

México es un país con problemas ancestrales de seguridad alimentaria. Por el lado de la producción, desde mediados de los setenta el país se ha visto incapaz de producir los alimentos básicos que requiere, cuando anteriormente había mantenido durante muchos años un superávit alimentario. Por el lado del consumo, importantes sectores de la población presentan serios problemas de subalimentación. Aunquela tendencia a la baja en el crecimiento de la producción agrícola ya se había manifestado desde el periodo de 1966 a 1976, fue hasta 1980 cuando la balanza agrícol a comenzó a presentar saldos negativos. La respuesta del gobierno a este fenómeno de inseguridad alimentaria fue la estructuración, por primera vez en México, de una política alimentaria integral que consideraba todas las fases de la administración agrícola, desde la producción hasta el consumo. Esta "estrategia", conocida como Sistema Alimentario Mexicano (SAM) contribuyó significativamente a clarificar el problema alimentario, pero no avanzó en su resolución.

Por el lado de la producción, el SAM tenía como objetivo central el 
logro de la "autosuficiencia alimentaria". Con la autosuficiencia se planeaba reactivar la producción agrícola mediante el apoyo del gobierno al productor de temporal, lo que implicaba su recapitalización y conversión en demandante de bienes de consumo y de capital. Por el lado del consumo se pretendía elevar la educación alimentaria de los sectores social es económicamente deprimidos, los cuales, con mayor ingreso, demandarían más y mejores productos. Se intentó concientizar a los sectores urbanos de escasos recursos sobre las ventajas alimenticias de la dieta tradicional (SAM 1980; Gridle 1983).

EI programa del SAM Ilegó a abarcar veinte "áreas de trabajo", a las que se integraban las diversas dependencias del gobierno relacionadas con la alimentación. Éstas, supuestamente coordinadas por el SAM, con recursos financieros provenientes del petróleo, canalizaron sustanciales recursos hacia el sector agrícola. El éxito del programa de autosuficiencia alimentaria -planteado en los términos anteriores- dependía de la adecuada coordinación de las diferencias instancias de la administración pública federal relacionadas con el campo y de recursos suficientes para su ejecución, en tanto los canales de comercialización fueran convenientemente establecidos y los productores (sobre todo eji datarios y pequeños propietarios) pudieran defenderse por sí mismos (Martínez 1990:363).

Un problema fundamental, no resuelto, era que la autosuficiencia alimentaria, sustentada en una estructura de producción ineficiente quedaba solamente en buenos deseos. Las prácticas corporativistas y clientelares sustentadas en el gasto público, las regulaciones excesivas que distorsionan y burocratizan las actividades económicas y la vida interna de las organizaciones sociales, constituían mecanismos de control político y no factores de fomento a la producción (Gordillo, 1992:12).

La falta de respuesta productiva de mecanismos como el crédito, el seguro, la producción, venta y distribución de fertilizantes, agroquímicos y semillas mejoradas, la administración de precios y subsidios, la transferencia de tecnología, hacían imposible avanzar hacia la autosuficiencia alimentaria.

Cuando los recursos financieros dejaron de fluir, no sól o el Programa 
no se expandió (de veinte áreas se pusieron en práctica no más de cinco), sino que ni siquiera pudo continuar operando. Ya en 1991 el colapso económico le impidió allegarse los recursos que requería para el cumplimiento de las acciones de la amplia burocracia que había generado, en especial la directamente involucrada con los productores. Y el colapso político de sus coordinadores Ilevó al Sistema a su entierro oficial a principios de 1983 (Martínez, :363).

En cuanto a la seguridad alimentaria como concepto, ésta no se mencionó durante el periodo del SAM. La politización del de autosuficiencia y el deseo de evitar su contaminación impidió realizar un análisis lúcido de su correlación con el de seguridad alimentaria. En su aspecto político, la autosuficiencia en la producción de alimentos se manejó como parte de la soberanía nacional.

Con el cambio de gobierno, el SAM se desmanteló. Los programas más operativos de éste, como el de crédito y de riesgo comparti do (vigentes hasta la fecha), se integraron al Programa Nacional de Desarrollo Rural Integral (Pronadri). Con una visión más simple, la política agrícola de la siguiente administración gubernamental convirtió la autosuficiencia alimentaria en un Programa de Soberanía Alimentaria que buscaba la eficiencia y la productividad del campo. Lo que fue la estrategia gl obal del SAM se convirtió en el Programa Nacional de Alimentación (Pronal), al cual se le dio una función solamente normativa.

En la actualidad, desde el punto de vista de la autosuficiencia, México continúa dependiendo de los alimentos básicos del exterior para completar la dieta de su población. La balanza agrícola fue deficitaria en siete años del decenio de los ochenta, y continúa siéndolo hasta ahora, no obstante la disminución de la dependencia en maíz y frijol (los principales alimentos de M éxico) en que, a finales del decenio anterior, se había llegado a adquirir en el exterior más del diez por ciento de los requerimientos. En el caso del arroz, el superávit manifiesto hasta 1988 se convirtió, los siguientes tres años, en déficit cada vez más marcado. En oleaginosas, el déficit es significativo; de éstas, el déficit en soya determina la balanza de la rama. En síntesis, la autosuficiencia de México en granos básicos tiene una gran aleatoriedad, que sólo podrá eliminarse con la producción sostenida y programada de los bienes 
considerados estratégicos.

En la presente etapa, la modernización de la agricultura, además de los profundos ajustes en las estructuras formales y productivas, implica su inclusión en los mercados internacionales de alimentos e insumos. Continuando con su función normativa, Ia Comisión Nacional de Alimentación diseñó, sobre las bases anteriores, el Programa Nacional de Alimentación 1990-1994 (Comisión Nacional de Alimentación:1990). En el Programa Nacional de Alimentación se definen con claridad conceptual los términos de soberanía, seguridad y "suficiencia" alimentarias. A la letra dice: "La Seguridad Alimentaria propugna garantizar en todo momento la existencia de un volumen suficiente de alimentos para satisfacer la demanda creciente del abasto nacional, la cual deberá ser apoyada con incrementos graduales y sostenidos en la producción interna; ello demanda una reestructuración profunda en los sistemas de producción primaria e implica, sobre todo, robustecer la capacidad productiva del campo, lo que deberá traducirse en mejores niveles de bienestar para la población rural y en una mayor oferta de alimentos". Líneas más adelante, en el mismo documento, se establece que "seguridad alimentaria implica también garantizar la disponibilidad de alimentos con estabilidad de precios", y que "seguridad alimentaria, en su concepción íntegra, presupone la necesidad de crear condiciones sociales, económicas y culturales que posibiliten un acceso efectivo de la población a los alimentos existentes y disponibles". En el mismo Programa se establece además que la "soberanía alimentaria se sustenta en la facultad de autodeterminación del Estado Mexicano para establecer los criterios rectores relacionados con la atención de las necesidades alimentarias básicas de la población, conforme a sus requerimi entos de cantidad, calidad y oportunidad". Y continúa: "La salvaguarda y ejercicio pleno de la Soberanía Alimentaria implica también asumir los lineamientos de política y acción que fortalezcan la autodeterminación de los patrones de producción y consumo y vigoricen la estructura interna del proceso alimentario en su conjunto, sin demérito de promover, a partir de una mejor inserción de México en el mundo, el aprovechami ento pleno de las oportunidades y ventajas comparadas que favorezcan a los intereses fundamentales de la nación". Por su parte, 
la "disponibilidad de los alimentos con estabilidad en los precios significa avanzar en la modernización de los sistemas de comercialización y distribución, reduciendo las fluctuaciones e ineficiencias que caracterizan a los canales que abastecen principal mente a los sectores populares de menores recursos".

En la propuesta alimentaria de la Comisión Nacional de Alimentación desaparece el concepto de autosuficiencia alimentaria. En el cuerpo del documento, y de manera casi imperceptible al referirse a los "esquemas de coordinación intersectorial, interinstitucional e interregional", se menciona que éstos se establecen para lograr la "suficiencia, disponibilidad y acceso a los alimentos".

Al margen del esfuerzo de definición conceptual antes descrito, las propuestas anteriormente señaladas no fueron tomadas en cuenta. Cada dependencia del gobierno o institución ha realizado sus acciones de carácter alimentario siguiendo la línea central de apertura económica e integración a los mercados internacionales. El programa, del que no se derivan líneas de acción aplicables, queda como un documento de referencia, sin obligatoriedad; ni siquiera en el apego a sus planteamientos y definiciones.

Los documentos que establecieron la línea a seguir en esta materia fueron el Programa Nacional de Modernización del Campo, 1990-1994 y el Programa de Ajuste del Sector Agropecuario (SARH, 1990-1; SARH, 1990-2) elaborados en la Secretaría de Agricultura y Recursos Hidráulicos. El primero de éstos establece como su objetivo fundamental "aumentar la producción y la productividad del campo, Ilevando justicia a las familias de los productores. Esto garantizará el abasto nacional y permitirá al país al canzar la soberanía alimentaria". Entre los objetivos particulares se menciona el de "Asegurar el abasto y la soberanía alimentarios dentro de un programa de apertura comercial, logrando un superávit en el intercambio de este renglón de la actividad".

En el trabajo cotidiano de coordinación de acciones relacionadas con la producción de alimentos, los términos de seguridad, autosuficiencia y soberanía alimentarias se utilizan en una correlación muy estrecha y

5 El Secretario de Agricultura y Recursos Hidráulicos, al referirse a la necesidad de producir internamente los granos básicos (maíz, frijol, arroz y trigo) que demanda la población, planteó que la "esencia de la soberanía alimentaria" radica en la 
conceptualmente con mucha laxitud. ${ }^{5}$

L a apreciación de estos aspectos, como en toda sociedad, no está exenta de contradicciones. Dentro de las élites de poder, de los sectores relacionados con la producción y de la academia, se expresan puntos de vista divergentes, que van desde el apoyo a las medidas gubernamentales hasta la oposición con todos sus matices. Pero en la práctica lo que determina las acciones es la posición que propugna o apertura hacia el exterior y la liberalización interna, como ha quedado manifiesto con las negociaciones en materia agrícola del Tratado de Libre Comercio y en las acciones previas a la firma de este documento, entre las que se cuentan la modificación de los esquemas de subsidio a la producción, la desgravación a las importaciones de los principales insumos agropecuareios, incluyendo fertilizantes, maquinaria agrícola y medicamentos veterinarios y los preparativos para establecer la bolsa agropecuaria.

\section{Conclusiones}

La seguridad alimentaria es un objetivo al canzable para la humanidad. En la actualidad, y en un futuro previsible, la capacidad mundial de producción de alimentos es suficiente para alimentar a la población del planeta.

Al concepto de seguridad alimentaria se le han dado diversas interpretaciones al utilizarse como sinónimo de otras nociones más o menos cercanas a éste, como son la autosuficiencia, soberanía e independencia alimentarias. La utilización laxa del término ha contribuido a diluir su contenido.

En el sector académico se han realizado importantes esfuerzos por esclarecer, delimitar y darle firmeza conceptual al término; tarea indispensable si se le quiere utilizar como herramienta en el campo de la ciencia social. A este esfuerzo se han sumado también algunos organismos internacionales preocupados por el desarrollo y la coopera-

\footnotetext{
"producción suficiente de maíz, frijol, trigo y arroz, para satisfacer nuestras necesidades". Esta misma idea se maneja como "evitar la dependencia en materia de alimentos" (El Financiero,4 de marzo de 1992, p.32). En otra intervención subraya que el campo depende de la soberanía y la fuerza del país; "si no tenemos soberanía alimentaria, la otra soberanía es cuestionable”. Enseguida añadió que la eficiencia en la producción de alimentos básicos es ya cuestión de seguridad nacional (El Financiero,14 de mayo de 1992, p.29).
} 
ción a nivel mundial.

Sin embargo, el avance en la clarificación del problema de inseguridad alimentaria no ha Ilevado a propuestas realistas de solución. Las políticas propuestas, por lo general, reflejan los intereses particulares de quienes las proponen y/o el apego a medidas económicas neoliberales que no toman en cuenta los aspectos políticos y sociales, lo que les da un alto grado de peligrosidad y genera temores en quienes tendrían que instrumentar tales medidas.

El concepto de seguridad alimentaria se encuentra con mayor claridad en países donde se presentan mayores problemas de seguridad alimentaria, en especial en el sentido de autosuficiencia productiva de alimentos básicos. En un país, o en una comunidad de países, la seguridad alimentaria surge también con las crisis de alimentos.

En J apón, la literatura sobre seguridad alimentaria -desde la óptica de la autosuficiencia- es muy amplia, tanto en lo que se refiere a producción de alimentos básicos, como a los niveles de consumo de nutrientes de las familias. En este país, la política de distribución del ingreso aplicada por el Estado desde los años sesenta ha tenido efectos positivos en los niveles de nutrición de la población, lo que le da un alto grado de seguridad alimentaria familiar. La disminución de la autosuficiencia alimentaria se suple con el reforzamiento de sus lazos de intercambio alimentario con el exterior.

En China, el manejo de la seguridad alimentaria (autosuficiencia) ha estado acompañado de una elevada carga política. Actualmente se percibe una clara preocupación por el evar la productividad agrícola y por aumentar el ingreso de la población, pero dejando que las fuerzas del mercado abran el rango de desigualdad social. Pareciera que han retomado el viejo principio de crear riqueza para después repartirla. En este contexto, el concepto general de la seguridad alimentaria está poco claro.

En Estados Unidos, Ia legislación agrícola y seguridad social considera los aspectos básicos de la seguridad alimentaria: producción, protección, distribución, comercio exterior, reservas, donaciones, etcétera. Específicamente a la Ley de Seguridad Alimentaria de 1985 se le dio ese nombre, aunque fundamentalmente forma parte de una tendencia 
iniciada en los años treinta, de asegurar la viabilidad de este sector con la intervención del Estado y la delimitación del "libre mercado"; aunque existen voces discordantes sobre la continuación de este esquema. Las preocupaciones de Estados U nidos sobre seguridad alimentaria trascienden sus fronteras nacionales para ubicarse en un contexto mundial. Sabedor de su responsabilidad para alimentar a muchos países deficitarios, dada su excelente dotación de recursos, su tecnología y nivel de productividad, permanece vigilante de la situación agrícola mundial.

EI caso de México, con una amplia experiencia en esta materia, ha establecido una clara definición conceptual sobre seguridad alimentaria. La experiencia alimentaria va desde ser un país superavitario, hasta la pérdida de la autosuficiencia y los esfuerzos infructuosos por recuperarla. En cuanto a nutrición, se aprecia la convivencia de un amplio sector con problemas alimentarios, junto con sectores privilegiados poseedores de dietas distorsionadas por la ingestión excesiva de nutrientes, situación que se relaciona con las disparidades en el ingreso. Los claros planteamientos sobre seguridad alimentaria se han quedado en esquemas conceptuales sin aplicación.

La falta de seguridad alimentaria es obra del hombre, no de la naturaleza, por mucho que se llame la atención a los desastres naturales (inundaciones y sequías) de algunas zonas, las cuales son compensadas con las buenas cosechas de otros años y/o de otras regi ones. Sin embargo, la desinformación e información tendenciosa del momento provocó una reacción exagerada de los mercados que el evaron exageradamente los precios en perjuicio de los países deficitarios. Desde entonces varios países se propusieron evitar la dependencia alimentaria, para lo cual estimularon su producción haciendo a un lado las leyes del mercado.

En última instancia, la seguridad alimentaria y los problemas del medio ambiente, que tarde o temprano se revierten sobre la primera, son asuntos políticos que sólo pueden ser resuel tos por la acción de los gobiernos: hacia arriba con la coordinación con otros Estados y hacia abajo con el apoyo de la sociedad organizada.

Por ello, la acción gubernamental puede aumentar o disminuir las oportunidades reales de un país y sus familias para obtener la seguridad al imentaria. De ahí también el señalamiento de que una de las funciones 
más importantes de todo gobierno sea el encontrar los mecanismos para que el suministro de alimentos para la sociedad no esté sujeto a las veleidads l' clima, de los mercados internacionales, ni del chantaje político.

1 A guayo, Q. Sergio y Michael, B. Bruce (1990). En busca de la seguridad perdida.México, Siglo XXI.

2 A lamgir, Mohiuddin y Arora, Poonam (1991). Providing food security for A lllnternational Fund for A gricultural D evelopment (IFAD). N ew York U niversity Press.

3 A llen, Patricia y Sach, Carolyn. "Sustainable agriculture in the U nited States: engagements, silences, and possibilities for transformation", en Allen, Patricia (Edit.) Food for the future: conditions and contradictions of sustainability.hn W illey and Sons, Inc. N ew York, 1993.

4 Banco Mundial (1986). Poverty and hunger.W ashington, D.C., W orld Bank.

5 Barnes, E. Harry, (1967). Historia de la economía del mundo occidental.México, UTEHA.

6 Barraclough, L. Solon (1991). An end to hunger?: the social origins of food strategies.ondres, Zed Books Ltd.

7 Berlan, Jean-Pierre (1991). "The historical roots of the present agricultural crisis", en Fiedland, H. W illiam, et. al. Towards a new political economy of agricultur B.oulder, W estview Press, pp.115-136.

8 Clancy, L. Katherine (1993). "Sustainable agriculture and domestic hunger: rethinking a link between production and consumption", en Allen, Patricia. Food for the future: conditions and contradictions of sustainability ew York, John W iley \& Sons.

9 Comisión N acional de A limentación (1990). Programa N acional de A limentación 1990-1994.Comisión N acional de A limentación, agosto de 1990.

10 Crook, W . Frederick (1985). "The Baogan D ohu incentive system: translation and analysis of model contract", China Q uarterly,102, junio de 1985, pp.291-303. 
Bibliografía
11 Curran, Teresa (1990). The theory and practice of agricultural policy.W ashington, Economic Development Institute of the W orld Bank.

12 D eW itt, B. Calvin (1992). "Ethics, ecosystems and enterprise, discovering the meaning of food security and develo pment". Smith Katie y Yamamori Tetsunao (Edits.) Growing our future: food security and environmentll est H artford, Connecticut, Kumarian Press.

13 D ixit, M. Praveen y Shwu-Eng W ebb (1991). Changes in China's consumption patterns: implications for international grain trade, Ponencia presentada en la XXI International Conference of A gricultural Economists. Tokio, Japón, agosto 22-29 de 1991.

14 Falk, Reyes Melba (1994). "El sector agrícola de Japón: el proteccionismo y sus efectos". En Comercio ExterioMéxico, abril de 1994.

15 FA O, (1987). Anuario de ProducciólfA O . Roma, 1988, p.67.

16 FAO, (1975). A provisional study of the measurement and use of the concept of self-sufficiencyRoma, 0 rganización de las $\mathrm{N}$ aciones Unidas para la A gricultura y la Alimentación.

17 FA O , (1993). Serie Informática Estadística.Roma, O rganización de las $\mathrm{N}$ aciones Unidas para la A gricultura y la A limentación.

18 Gabinete de Comercio Exterior. El proceso de adhesión de México al Acuerdo General Sobre Aranceles A duaneros y Comercio (GATTG,abinete de Comercio Exterior, 1986, p.12.

19 G avaldón, E. Enrique, Javier Ceceñas E. (1990). "La política agrícola de Estados Unidos". Comercio Exterio diciembre de 1990.

20 Glaser, K. Lewrene (1986). "Provisions of the Food Security Act of 1985", en A griculture Information Bulletiil 0. 498, W ashington, abril de 1986.

21 Gordillo, G ustavo (1992). "¿A gricultura social Versus agricultura de mercado?", en Renglones N 0. 22, abril-julio de 1992, pp.19-25.

22 Grindle, S. Merilee (1983). Issues in U.S.-M exican agricultural relations: a binational consultationsan $D$ iego, Center for U.S.Mexican Studies, University of C alifo rnia. Monograph Series, 8.

23 Hallberg, M.C. (1992). Policy for American agriculturAmes, lowa State University Press.

24 Hayami, Yujiro (1975). A Century of A gricultural Growth in Japan. University of Tokyo Press. Tokio, 1975. 
Bibliografía
25 Hayami Yujiro y Ruttan W. Vernon (1989). Desarrollo agrícola: una perspectiva internacionalM éxico, Fondo de Cultura Económica.

26 Hazell, Peter (1993). "Implication of grain trade liberalization for LDC food security". Reinsel, D. Robert. Managing food security in unregulated marketsBoulder, W estview Press.

27 Herrera-Lasso, M. Luis y González, G. Guadalupe (1990). "Balance y perspectivas en el uso del concepto de la seguridad nacional en el caso de México", en A guayo, Q . Sergio y Michael, B. Bruce, En busca de la seguridad perdidaMéxico, Siglo XXI.

28 Kellogg, D. Earl (1991). "A n overview of agricultural selfsufficiency in developing countries", en Ruppel, J. Fred y Kellogg $D$. Earl (edit.) $\mathrm{N}$ ational and regional self-sufficiency go als: implications for international agricultur B.oulder, Lynne Rienner Publishers, pp.231-243.

28 Lardy, R. N icholas (1986-1). "Prospects and some policy problems of agricultural development in China", A merican Journal of A gricultural Economid\&,ol. 68, N úm. 2, mayo 1986, pp.451-457.

30 Lardy, R. N icholas (1986-2). "A gricultural reforms in China", Journal of International Affair\$/ol. 39, N úm. 2, invierno de 1986, pp.91-104.

31 Lin, Justin Yifu (1987). Household farm, cooperative farm, an efficiency evidence from rural decollectivization in China Economic G rowth Center, W ork Paper N úm. 533, Yale University.

32 Meadows, L. Dennis, et. al. (1972). Los límites del crecimiento. México, Fondo de Cultura Económica.

33 Martínez, Saldaña Tomás (1990). "A gricultura y Estado en México". En Rojas Teresa, La agricultura en tierras mexicanas desde sus orígenes hasta nuestros díasM éxico, $G$ rijalbo.

34 McMillan, John, et. al. (1988). The impact of China's economic reforms on agricultural productivity growtmimeo.), G raduate School of International Relations and Pacific Studies. University of California, San Diego, Research Report 88-02, octubre de 1988.

$35 \mathrm{~N}$ aciones U nidas (1993). Estudio económico mundial 1993. $\mathrm{N}$ aciones $\mathrm{U}$ nidas. 


\section{Bibliografía}

36 Paulino, Leonardo A. (1986). Food in the third world; past trends and projections to 2000|FPRI Report, N úm. 52, W ashington, IFPRI, junio de 1986, FAO .

37 Rukuni, Mandivamba y Eicher, K. Carl (1991). "Food security policy options in Eastern and Southern A frica", en Ruppel, J. Fred y Kellogg, D. Earl (edit.) N ational and regional selfsufficiency goals: implications for international agriculturoulder, Lynne Rienner Publishers, pp.89-107.

38 Ruppel, J. Fred (1991). "International agricultural trade and fo od self-sufficiency", en Ruppel, J. Fred y Kellogg, D. Earl (Edit.) $\mathrm{N}$ ational and regional self-sufficiency goals: implications for international agricultureBoulder, Lynne Rienner Publishers, pp.197-215.

39 SAM (1980). Primer planteamiento de metas de consumo y estrategia de producción de alimentos básicos para 1980-1982. Sistema A limentario Mexicano (mimeo.).

40 Sanderson, H. Fred (1978). Japan's food prospects and policies, W ashington, The Brookings Institution.

41 SARH (1990-1). Programa Nacional de Modernización del Campo, 1990-1994. Secretaría de Agricultura y Recursos Hidráulicos, en Comercio Exterio octubre de 1990.

42 SARH (1990-2). Programa de Ajuste del Sector A gropecuario (Resumen Ejecutivo,)Secretaría de Agricultura y Recursos Hidráulicos, (mimeo.) 17 de octubre de 1990.

43 Schu, Edward G. (1986). "Making food policy in a new international environment", en Mann, K. Charles y Huddleston, Barbara, Food policy: frameworks for analysis and actiolndiana University Press, Bloomington, 1986.

44 Shenggen, Fan (1991). "Effects of technological change and institutional reform on production growth in chinese agriculture", en A merican Journal of A griculturdy,ol. 73, N 0. 2, mayo de 1991.

45 Siamwalla, A mmar y Valdés, Alberto (1991). "Seguridad alimentaria en los países en vías de desarrollo: aspectos internacionales", en Staats, Eicher K. y Carl, M. John (Comp.). Desarrollo agrícola en el Tercer Mundlld éxico, Fondo de Cultura Económica.

46 Staatz, M. John (1991). "Conceptual issues in analyzing the economics of agricultural and food self-sufficiency", en Ruppel, 
Bibliografía
J. Fred y Kellogg, D. Earl (Edit.) N ational and regional selfsufficiency go als: implications for international agriculturisoulder, Lynne Rienner Publishers, pp.13-25.

47 Timmer, C. Peter, Falcon, P. W alter y Pearson, R. Scott (1985). A nálisis de políticas alimentariasEspaña, Edit. Tecnos.

48 U nited N ations (1993). Report on the world social situation 1993. Department of Economic and social D evelopment, $\mathrm{N}$ ew York, United $N$ ations.

49 W esley, E. y Peterson, F. (1991). "Structural A djustment and food security in developing countries", en Ruppel, J. Fred y Kellogg, D. Earl (edit.) N ational and regional self-sufficiency goals: implications for international agricultur\&,oulder, Lynne Rienner Publishers, pp.215-231.

50 Zweig, D avid. "Peasant, ideology and new incentive systems: Jiangsu Province, 1978,1981", en Parish, W illiam L., ed. Chinese rural development; the great transformatiolm.. E. Sharpe, Inc., A rmonk, $\mathrm{N}$ ew York.

51 W atson, Andrew (1984). "A griculture looks for 'shoes that fit': the production responsibility system and its implications". En Maxwell N . y McFarlane, Eds., China's changed road to development, $\mathrm{xford}$, Pergamon, 1984.

52 - Food Security Act of 1985J.S. Code Congressional and A dministrative N ews, 99th. Congress, 1st. Session, 1985, p.1,354.

53 - Satellite technology and world food securiselect Committee on H unger, U.S. House of Representative, U.S. Government Printing 0 ffice, W ashington, 1989.

54 - Economic Report of the Presidert..S. Government Printing O ffice, W ashington, 1987. 